\title{
BMJ Open Infertility-related distress and clinical targets for psychotherapy: a qualitative study
}

\author{
Loveness Dube, ${ }^{1}$ Nokuthula Nkosi-Mafutha, ${ }^{2}$ Ashley A Balsom, ${ }^{1}$ \\ Jennifer L Gordon (D) ${ }^{1}$
}

To cite: Dube L, NkosiMafutha N, Balsom AA, et al. Infertility-related distress and clinical targets for psychotherapy: a qualitative study. BMJ Open 2021;11:e050373. doi:10.1136/ bmjopen-2021-050373

- Prepublication history for this paper is available online. To view these files, please visit the journal online (http://dx.doi. org/10.1136/bmjopen-2021050373).

Received 18 February 2021 Accepted 13 October 2021

\section{Check for updates}

(C) Author(s) (or their employer(s)) 2021. Re-use permitted under CC BY-NC. No commercial re-use. See rights and permissions. Published by BMJ.

${ }^{1}$ Department of Psychology, University of Regina Faculty of Arts, Regina, Saskatchewan, Canada

${ }^{2}$ Department of Nursing Education, University of the Witwatersrand, JohannesburgBraamfontein, South Africa

Correspondence to Dr Jennifer L Gordon; jennifer.gordon@uregina.ca

\section{ABSTRACT}

Objectives An estimated $30 \%-40 \%$ of women attending infertility tertiary care facilities experience clinically significant depression and anxiety. However, current psychological interventions for infertility are only modestly effective in this population. In this study, we aimed to identify the specific psychological components of infertility-related distress to assist in the development of a more targeted and effective therapeutic intervention. To our knowledge, this study is the first of its kind to include the views and opinions of mental health professionals who specialise in the field of infertility and the first to explore therapies currently used by mental health professionals. Design A qualitative approach using semistructured individual interviews and focus group interviews with women who have experience with infertility and also mental health professionals specialising in the field of infertility. Thematic analysis was used to identify patterns and themes emerging from the data.

Participants Twenty-one women (aged 25-41 years) struggling to conceive for $\geq 12$ months and 14 mental health professionals participated in semistructured interviews about the psychological challenges related to infertility.

Results Five themes, each divided into subthemes, emerged from the data and these were developed into a model of infertility-related distress. These five themes are: (1) anxiety, (2) mood disturbance, (3) threat to self-esteem, identity and purpose, (4) deterioration of the couple and (5) weakened support network. In addition, therapeutic techniques used by mental health professionals were identified.

Conclusions The results of this study suggest specific clinical targets that future interventions treating infertilityrelated distress should address.

\section{INTRODUCTION}

Globally, $15 \%$ of couples are affected by infertility, ${ }^{12}$ typically defined by the failure to achieve a clinical pregnancy after 12 months or more of regular unprotected sexual intercourse. ${ }^{3}$ While male and female factor infertility are roughly equivalent in prevalence, ${ }^{4}$ it is well documented that women generally bear the brunt of infertility-related burden, both physically and mentally, regardless of the cause. ${ }^{56}$ In fact, research suggests that

\section{Strengths and limitations of this study}

The study adopted a patient-oriented approach and included interviews with mental health professionals specialising in infertility.

- The qualitative approach provided an in-depth sociocontextual and detailed description and interpretation of the experiences of infertile women.

- The different data collection methods (interviews and focus groups) with two different sources of data (women and mental health professionals) enriched the available data.

- All participants were in heterosexual relationships, perhaps preventing the discovery of themes specific to same-sex couples.

an estimated $30 \%-40 \%$ of women attending infertility tertiary care facilities experience clinically significant depression and anxiety $^{7-10}$ and the rates are equally high in non-treatment-seeking infertile women. ${ }^{11}$ At least half of infertile women have described infertility as the most upsetting event of their lives and their distress has been found to be comparable with that of people with other chronic diseases like cancer. ${ }^{12}$ Infertile women also reported feelings of shame, selfblame, grief, loss, anger, sadness and lack of femininity. ${ }^{13} 14$

Despite the high rates of distress in this population, one meta-analysis suggests that current psychological interventions-most of which are merely modified versions of existing therapeutic approaches targeting general depression and anxiety-are only modestly effective in this population. ${ }^{15}$ Though they were found to result in small reductions in anxiety, they were not found to improve depressive symptoms, infertility distress or marital functioning when adjusting for publication bias. Furthermore, the overall effect size associated with randomised controlled trials of psychological interventions on combined psychological outcomes 
was non-significant and efficacy was not found to differ according to intervention type. There is therefore a great need to develop a new psychological intervention that is more effective in reducing infertility-related distress. We propose to do so by starting with a careful look at the specific clinical targets that an infertility-specific intervention should address. The purpose of the current study was, therefore, to identify the unique psychological challenges faced by women struggling with infertility as well as identify other psychotherapeutic approaches that have yet to be used in the treatment of infertility-related distress. We therefore aimed to interview both women themselves and mental health professionals who specialise in treating this population. An inductive approach was then taken to identify the major themes and subthemes characterising infertility-related distress as well as to identify the major therapeutic approaches used by mental health professionals in treating this condition. To our knowledge, this study is the first of its kind to explore the unique psychological challenges faced by women struggling with infertility through the eyes of the mental health professionals who specialise in this field. Furthermore, it is the first to explore the current therapies applied by mental health professionals in treating infertility-related distress.

\section{METHODS}

\section{Study design}

This study employed a qualitative approach using semistructured interviews to explore the experiences of women and mental health professionals. The qualitative approach was chosen with the aim of providing in-depth detailed description and interpretation of the psychological challenges faced by infertile women. ${ }^{16}$

\section{Patient and public involvement}

A panel of six women who were not study participants and who had experience with infertility collaborated with the researchers at two stages in this research. First, at the development of semistructured interview guides and second, during the final stages of data analysis in the naming of the themes and subthemes.

\section{Participants and sampling}

The target population included (1) women who were experiencing either primary or secondary infertility, and (2) mental health professionals specialising in the field of infertility. Purposive and snowball sampling strategies were used to recruit both women and mental health professionals. ${ }^{17}$ To recruit women, flyers were posted in a local fertility clinic and an advertisement was posted on the Facebook page of a local infertility support group. Eligible participants were 18 years or older and had personal experience with infertility.

Eligible mental health professionals included Masters and PhD-level clinical psychologists, counselling psychologists, and social workers throughout Canada and the USA who had a self-reported specialisation in infertility.
Box 1 Example of questions from the semistructured interview guides

\section{Women with infertility}

- What are the daily emotional challenges that you face as you have struggled to conceive?

- Throughout the whole process, when have things been the hardest for you?

- What have your interactions with the medical community been like throughout your fertility struggles?

- What have your interactions with your family and friends been like throughout your fertility struggles?

\section{Mental health professionals}

- In your experience, what are the most common/specific challenges or symptoms that women present with and seek help for?

- In your practice, what techniques or therapeutic approaches have you found to be most helpful in helping women struggling with infertility?

Eligible mental health professionals were identified via a broad internet search of clinicians affiliated with or endorsed by an infertility clinic, and clinicians in private practice advertising a specialisation in infertility. Those identified through the search were invited via email to participate.

\section{Setting}

Face-to-face interviews and focus group discussions were conducted at the research site at the University of Regina. Other interviews were conducted over the phone.

\section{Data collection}

Data were collected using two semistructured interview guides (one for women and one for mental health professionals). The first interviews were pilot tests in order to refine the interview guides and the data were included in the analysis. Box 1 shows an example of questions included in both interview guides. Demographic information was collected via an online survey in Qualtrics ${ }^{18}$ for women with infertility and at the start of the phone interview for mental health professionals. Focus group discussions for female participants were chosen as a preferred method of data collection as they encourage participants to explore topics that are seldom discussed, ${ }^{19}$ though the option of an individual interview was provided for those preferring to maintain privacy. Telephone interviews were conducted only when face-to-face interviews were not logistically possible. All mental health professional interviews were conducted by phone. Data for both women and mental health professionals were collected until saturation was achieved (ie, new information was no longer generated).

Focus group interviews lasted 2 hours and individual interviews (face-to-face and telephone) lasted between 40 and $60 \mathrm{~min}$. Two moderators were present during focus group interviews, one facilitating the discussion, and the other as an observer and note-taker. LD conducted all individual interviews with women. The length of each 
professional interview ranged from 30 to $100 \mathrm{~min}$, with an average of $60 \mathrm{~min}$. Member checking was achieved by paraphrasing and summarising the participant's contributions during focus groups and interviews. The researchers took field notes, and all interviews were audio-recorded and transcribed for thematic analysis.

\section{Data analysis}

We followed the Consolidated criteria for Reporting Qualitative studies to comprehensively report on important features of a qualitative study. ${ }^{20}$ Preliminary data analysis was concurrent with data collection and was conducted independently by LD and NN-M. This analysis provided a means of determining data saturation through consensus from both authors. The main data analysis was conducted independently by two authors, LD and NN-M. JLG acted as an auditor of the data. Interview transcripts for women and for mental health professionals were analysed separately before comparing the emerging themes from the two groups. Disagreements in the analysis process were discussed and resolved by consensus. We adapted the phases of theme development as described by Vaismoradi et $a l^{16}$ to enable us to do a thematic analysis that also resonates well with the steps of qualitative content analysis. The thematic analysis was conducted in four phases, including initialisation (reading transcriptions and highlighting meaning units, coding and looking for abstractions in participants' accounts, writing reflective notes, classifying and comparing), construction (labelling, translating and transliterating, defining and describing, immersion and distancing), rectifying (relating themes to established knowledge, stabilising), and finalisation (developing the storyline). ${ }^{16}$ Final decisions about the naming of themes and subthemes were made in collaboration with the panel of women who had helped prepare the interview guides, mentioned above. Although we used different data sources (women and professionals) and data collection techniques (individual vs focus group interview), we compared the themes emanating from the two data sources. As the same themes related to both participant groups' experiences emerged in the analysis, it was decided that the results from both data sources and data collection methods would be merged, where applicable. NVivo (V.12) software was used to facilitate data management, coding and analysis (QSR International, 2019). ${ }^{21}$

\section{RESULTS}

Thirty-three women responded to the call for research participants and met eligibility criteria. Two focus groups of four participants each, seven individual face-to-face interviews and six individual telephone interviews were conducted. After 21 women had been interviewed, data saturation was achieved, and data collection was stopped. Table 1 shows the demographic characteristics of the female participants.
Table 1 Participant characteristics

Frequency

$\%$ or mean (SD)

\begin{tabular}{|lcc|}
\hline Age (years) & & \\
\hline $25-30$ & 4 & 19 \\
\hline $31-35$ & 7 & 33 \\
\hline $36-40$ & 6 & 28 \\
\hline 41 & 2 & 10 \\
\hline Not reported & 2 & 10 \\
\hline Education & & \\
\hline University degree & 15 & 71 \\
\hline High school diploma & 5 & 24 \\
\hline Not reported & 1 & 5 \\
\hline Marital status & & \\
\hline Married & 17 & 81 \\
\hline Single but cohabiting & 2 & 10 \\
\hline Single/never married & 1 & 5 \\
\hline Not reported & 1 & 5 \\
\hline Combined household income $(\$ C)$ & \\
\hline 113 000 and greater & 16 & 76 \\
\hline $90-112$ 999 & 2 & 9 \\
\hline $70-89$ 999 & 1 & 5 \\
\hline $35-49999$ & 1 & 5 \\
\hline Not reported & 1 & 5 \\
\hline
\end{tabular}

Ethnicity

Caucasian

21

100

Pregnancies carried full-term

\begin{tabular}{|ccc|}
\hline 0 & 11 & 52 \\
\hline 1 & 6 & 28 \\
2 & 2 & 10 \\
\hline 3 & 1 & 5 \\
\hline Not reported & 1 & 5 \\
\hline $\begin{array}{l}\text { Currently trying to conceive } \\
\text { Yes }\end{array}$ & \\
\hline No & 12 & 57 \\
\hline $\begin{array}{l}\text { Current time trying } \\
\text { Months }\end{array}$ & 9 & 43 \\
\hline Have pursued fertility treatments & 23.83 & $23.8(22.1)$ \\
\hline Yes & 18 & 86 \\
\hline No & 3 & 14 \\
\hline
\end{tabular}

Of the 121 mental health professionals contacted, 16 responded. Fourteen consented to participate in the study and completed the telephone interview. Eight participants were registered psychologists (four $\mathrm{PhD}$ and four Masters), three were registered psychotherapists (one $\mathrm{PhD}$ and two Masters) and three were registered social workers (Masters). All mental health professionals were women and most practitioners worked in private 


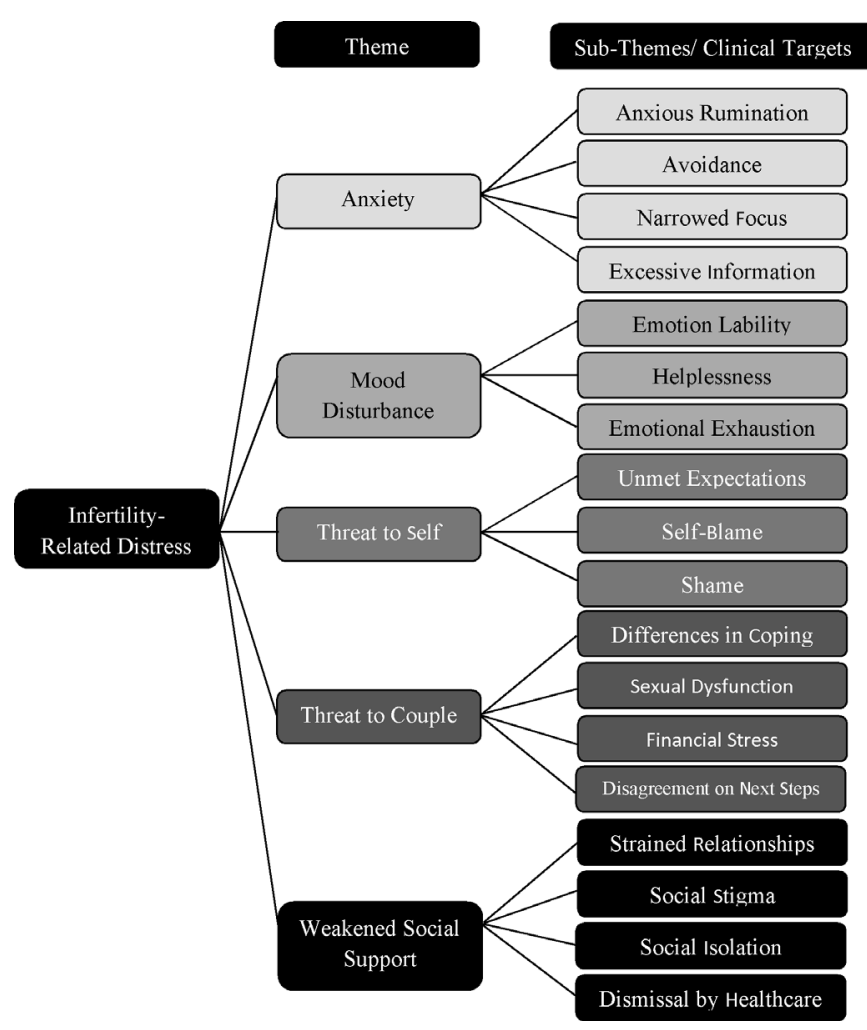

Figure 1 Model of infertility-related distress from identified themes and subthemes/clinical targets.

practice. All had at least 2 years of experience, while $75 \%$ had at least 5 years of experience.

\section{Psychological experiences of women}

Although data were analysed separately for women and health professionals, the themes and subthemes emerging from both groups relating to the psychological experiences of women proved to be very similar and are presented together. Findings from this study illuminated five important themes for the psychological experiences of women, which were developed into a model of infertility-related distress. These five themes are: (1) anxiety, (2) mood disturbance, (3) threat to self-esteem, identity and purpose, (4) deterioration of the couple and (5) weakened support network (figure 1). In the following section, themes will be discussed in detail, with supporting quotations provided from different participants, referenced with the following abbreviations where needed: individual interview (II), focus group (FG) and mental health professional (MHP).

\section{Anxiety}

Anxiety was perhaps the most highly endorsed aspect of infertility-related distress. Both the mental health professionals and women described relentless anxiety manifesting itself through multiple behaviours, described below, aimed at seeking reassurance and avoiding further distress.
Anxious rumination

Women with infertility reported anxiously thinking about their infertility, often to the point of 'obsession'. Both the women and mental health professionals described women's incessant thoughts about the causes and treatment of their infertility and monitoring of their menstrual cycle and symptoms that might indicate pregnancy, to be all consuming. One woman reflected: 'I was developing a lot of anxiety and spending so much time hovering about this like it was just becoming completely all consuming' (FG). One health professional considered anxiety to be the most prominent feature of infertility-related distress:

One of the primary emotional symptoms is anxiety... rumination over the uncertainty, and anxiety sometimes about the medical procedures, anxiety related to going to the fertility clinic... Anxiety related to just not knowing. (MHP)

\section{Avoidance of fertility reminders}

Many women reported feeling the need to avoid activities and social events that would expose them to reminders of others' fertility, such as family gatherings where pregnant women, children and babies would be present. Women also described avoiding social media to avoid seeing pregnant persons and birth announcements:

And then all of a sudden, birth announcements... pregnancy announcements start to bother you...You don't want to go on your social media because you just don't want to see everybody having fun with their babies and their families and getting pregnant... and you just feel like you're left behind. (II)

Mental health professionals also reported this avoidance as a frequently observation. "Everything and everyone can be very triggering," said one. Both women and professionals linked this avoidance of potentially triggering social situations with a gradual increase in social isolation and distancing from once close friends and family members.

\section{Narrowed focus on fertility-related activities}

It was mostly mental health professionals who made observations related to this subtheme by mentioning that, over time, women would increasingly focus on their attempts to conceive at the cost of their previously enjoyed activities. Events and plans would be put on hold for the sake of their treatments or 'in case' they became pregnant. The professionals also explained that, over time, getting pregnant often became the topic of every conversation within a couple and all actions and activities were solely focused on conceiving and the next steps in the process:

Fertility treatment becomes everything, it consumes their everyday life...A tendency for couples going through fertility [treatments] or struggling with infertility is that that's all they talk about, fertility and next steps. (MHP) 
Relatedly, one woman explained that the scheduling of fertility treatments often made it difficult to plan:

I hate that I can't plan stuff because we are still doing IVF [in-vitro fertilisation], we have embryos that are still on ice. And so, every try is three months apart and we love to travel but it's like you can't book because you don't know when exactly that next treatment is.... It's just that lack of being able to plan. (FG)

\section{Excessive information seeking}

Spending an excessive amount of time seeking information about the causes and potential treatment of infertility, usually via the internet, was described by both women and mental health professionals: 'Sometimes I do see... pure obsession, it can actually look like where the person is frantically researching online repeatedly for explanation as to why they haven't gotten pregnant' (MHP). Health professionals also voiced concerns that this constant searching for answers was potentially harmful for women as the information they obtained was often of questionable validity.

\section{Summary}

Every woman and health professional interviewed emphasised elements of anxiety related to infertility. Women who had undergone fertility treatments related their anxious rumination to the success of the many procedures involved in the treatment process while women who had only struggled to conceive without medical intervention reported being very focused on the different phases of their menstrual cycle, identifying signs of fertility and looking for signs that a cycle was positive. This excessive mental energy devoted to all things infertility, coupled with a desire to avoid witnessing evidence that others are conceiving without difficulty, resulted in a decreased engagement in previously enjoyed activities and an increase in social withdrawal. Anxiety as a theme was more prominent in focus groups and face-to-face interviews when compared with interviews conducted over the phone. We hypothesise that perhaps researchers were better able to build rapport in face-to-face interactions, allowing women to feel more comfortable sharing their challenges.

\section{Mood disturbance}

This theme captured women's experience of enormous fluctuations between positive and negative emotion, eventually leading to complete exhaustion and, in some cases, depression.

\section{Emotional lability}

As common as the confirmation of anxiety was the description of infertility as an 'emotional rollercoaster': at the start of each cycle, hope and excitement would build, only to be met with extreme disappointment and grief following each negative test or miscarriage:
Every month, you go through this cycle of excitement or hope and then followed by no success... You get depressed, you get very discouraged or very down... and then you think, 'Oh, I'm not going to invest any more energy', but then just by nature, you do. And then you get hopeful and excited again, and you just go through this rollercoaster of emotions that way.

Women who had undergone fertility treatments explained that their mood was highly dependent on the outcomes of each step in fertility treatments: ultrasounds, egg retrieval and embryo transfer. Some women also reported that the hormones taken for infertility exacerbated their emotional lability: 'The hormones that they have you on wreak havoc with my entire being, I felt crazy' (FG 2). Other women reported being overly sensitive or irritable in their daily lives because of their high stress levels, directly related to their struggles to conceive.

\section{Helplessness}

Several women stated that one of the biggest challenges related to infertility was the feeling of being completely helpless in the process of trying to conceive. Women reported feeling extremely frustrated by their lack of control over the outcome of any given cycle. One woman participating in a focus group lamented: 'One of the hardest aspects is the helplessness that I feel...because most of the things in my life-it's like okay, you do A B C $\mathrm{D}$ and you get this outcome but with this there's just no guarantees.'

One participant explained that the sense of a lack of control over the process led her to even contemplate not taking her medication so that she could at least have 'some sense of control over destiny'. Women also expressed frustration at the lack of information and choice regarding their treatment options: 'I feel like they have a very set order [in fertility clinics but] they are not going to tell you why this is the order in which they do things' (FG). Mental health professionals similarly remarked that women were given little opportunity to determine the course of their treatment in medical settings.

\section{Emotional exhaustion}

Female participants reported that the constant alternation between hope and despair, along with their feelings of helplessness, led them to become emotionally drained. One woman explained that fertility treatments had drained her to the point of requiring a mental health break from work: 'I went to the doctor and I said to her, 'I need to get off work, I need to be on stress leave because I can't do this anymore" (II). Another woman recalled a time when she had 'hit rock bottom' and became suicidal because of her difficulties conceiving.

\section{Summary}

Nearly all women reported that their mood dipped at certain points throughout their cycle each month, particularly after a negative outcome. Feelings of complete 
helplessness over the process and outcome of each cycle were also very prominent. A smaller subset of women, however, related the constant up and down from hope to despair to the development of emotional exhaustion and what sounds like clinical depression.

\section{Threat to self-esteem, identity and purpose}

This subtheme captured women's reports that infertility had contributed to a questioning of their identity and negative internal dialogue about their worth and the worth of their life in the absence of motherhood.

\section{Unmet expectations for self and one's future}

Many of the women reported an enormous sense of loss as they reflected on their childhood dreams of being a mother. One woman remembered:

When I was a kid, I wasn't dreaming about being a doctor or vet or thinking about the perfect wedding, I was thinking about being a mom. And it was just a sense that the vision of what I had for my future wasn't possible. (FG)

Mental health professionals added that for many women, motherhood was so closely tied to their identity as a woman that their infertility diagnosis threatened their very sense of who they were as a person:

The number one thing that I see and can identify hands down is there is an attack on their identity and their sense of self, the narrative that they believed about who they were, what their reproductive story was, and they feel very shattered from that because this story is not playing out. (MHP)

Health professionals also reported that women having to pursue third-party reproduction also grieve the loss of pregnancy in the case of surrogacy, and the loss of genetic connection to their child in the case of egg donation.

\section{Self-blame}

Several women reported believing that they were partly to blame for their infertility, particularly among women with female factor infertility: 'You have to deal with the mental aspect of knowing...that I was the reason that we didn't have kids... If [my husband] was with someone else, he could be having those kids' (II). Women also reported that they tended to question whether any of their behaviours might be contributing to their diagnosis or a failed cycle. One woman, a long-distance runner, recalled: 'A few of my IUIs [intrauterine inseminations] were right after doing a very long race and so I felt like maybe that's why it didn't work. I was blaming myself that it didn't work' (FG). Mental health professionals corroborated these reports.

\section{Shame}

Many women reported feeling ashamed of their diagnosis of infertility, seeing themselves as 'broken', leading them to keep their struggles a secret or to share with only a few close others: 'If I had cancer, it would have been open, and we could have talked about it and my community would have supported me. But when it's infertility, you feel different, isolated, and embarrassed, and ashamed' (II). Mental health professionals echoed the same sentiment, highlighting the difference between how infertility was perceived compared with other medical conditions.

\section{Summary}

Within this theme, we see that infertility often triggers an existential crisis of sorts: a profound questioning of what it means to be a woman in the absence of fertility and the potential for motherhood. Women were left wondering what their lives would look like and what value it might have if motherhood was never achieved. This seems to be particularly the case for women who reported having wanted to be a mother since childhood.

\section{Deterioration of the couple}

As one mental health professional reported, some relationships were strengthened by the process of struggling to conceive while others suffered to the point of divorce. The following challenges, however, appeared to be common even among couples whose relationship was strengthened overall.

\section{Partner differences in coping}

Women described their frustration related to differences in coping between themselves and their partners. It appears that women often took a more active role and expressed their emotions more openly than their partners, leading them to perceive their partners as being less emotionally invested in the goal of conceiving:

It makes me feel like I'm the one that's always worrying and stressing and thinking about things and making appointments and tracking my cycle and kind of carrying the burden in a way...He's just kind of very laid-back about the situation...it gets a little frustrating for me. (II)

Another woman reflected on her and her husband's different ways of coping with grief following a miscarriage:

The first time the miscarriage happened, my husband kind of grieved separately because he didn't want to grieve in front of me because he thought that it wouldn't help how I was doing with it...so I just thought like, 'Hey, we had a miscarriage, and he's fine.' (II)

Mental health professionals agreed that many challenges within the couple related to partners not 'processing' events surrounding infertility at the same pace.

\section{Negative impact on couple's sex life}

Women commonly reported a deterioration of the couple's sex life because, over time, the purpose of sex became solely to achieve conception rather than intimacy or enjoyment: 'it just seems like work' (II). One mental health professional described sex as becoming 'transactional' in nature and reported that women often found 
it difficult to engage without thinking about the goal of conceiving.

Stress related to financial burden of fertility treatments

Given the high costs of fertility treatments, for the most part not covered by medical insurance, women reported that strained finances became a prominent topic of conversation among couples pursuing assisted reproductive technologies:

Conversations around the cost of everything just because that puts a lot of strain on our relationship... How can we afford it?... How can we make it work? We don't really have time to wait and save up for this, we just have to figure it out now. (FG)

Concerns about finances would also lead to stressful discussions around the feasibility of continuing treatment. The same sentiment was echoed by the mental health professionals who described the financial strain brought on by fertility treatments as being a challenge for most couples.

\section{Couple disagreements on next steps}

A few women reported that tension within the couple arose due to differences in opinion about next steps to take in trying to conceive: 'I got divorced because... I think he was done before I was, he just didn't want to do it anymore' (FG). One woman recalled that she and her husband went into a doctor's appointment with very different intentions and expectations, which led to conflict afterwards:

I went in thinking like, 'Okay, we're going to get the information and move forward.' He went in thinking, 'Okay, I'm going in to get the information and then make a decision on that.' So, we were on different pages going in. (II)

\section{Summary}

While a few women reported that their relationships were strengthened overall because of going through the challenges of infertility together, all women referred to some difficulties within the couple at one time or another. A subset of women reported that their relationship had been severely tested (or severed) by their struggles with infertility and these serious conflicts seemed to be primarily related to differences in opinion regarding next steps to take regarding treatment.

\section{Weakened social support network}

The theme of weakened social support networks highlights female participants' struggles with their loved ones due to stigma and lack of education surrounding infertility. Women also reported that their experiences were often dismissed by health service providers.

\section{Strained relationships with friends and family}

Women explained that relationships with friends and family were often strained in the context of infertility, in part due to the barrage of unhelpful comments and questions they received from well-meaning loved ones. One woman explained why she felt that she could not open up to her friends about her infertility:

I have a lot of friends who mean well, and they just keep saying it'll happen...I just don't know what they want me to say to that... I feel like if I talk to them about it, they're just gonna be like, 'Oh just stay positive'. (FG)

Several women reported that their family members often showed a lack of understanding about the emotional pain they were experiencing, even when they were open with them about the challenges they were facing: 'All my mom said was that I was a $\mathrm{b}^{* * * *}$ that Christmas. And so, there was just no understanding' (FG). Participants also struggled with feelings of envy, jealousy and resentment towards friends or family who had conceived easily, which also contributed to distance with once close loved ones:

The relationship with my brother is still pretty strained. Him and his wife actually ended up getting pregnant five weeks before I did, and they only tried for a couple of days... and then got pregnant right away. ...I felt like they didn't deserve their pregnancy because they didn't have to work for it. (II)

\section{Social stigma}

Women reported that they perceived a great amount of social stigma related to infertility, which created anxiety around discussing it openly: 'I felt reluctant to tell friends and other people. And I still haven't told everyone in my life...just because I didn't want to be an object of pity, I didn't want anyone to think I was a barren woman' (II). Other women refrained from telling others about their infertility because they did not want to be judged by friends and family who might comment on the woman's potential role in contributing to her problems conceiving.

\section{Social isolation}

An increase in social isolation seemed to be a consequence of several processes-women's avoidance of fertility reminders (from theme 1), their attempts to avoid unhelpful comments and questions from others, and the pressure to hide their preoccupation with their infertility: 'I feel like it kind of closed off some of my opportunities for healthy, normal socialisation... and I think to some extent, that's impeded my ability to form closer relationships with people too' (II). For example, one participant recounted avoiding get-togethers at bars or pubs in order to avoid questions about why she was not drinking alcohol:

One of the things I find really difficult about trying to conceive is you can't just go for a casual night out with friends and have drinks... I have tried going out and just drinking non-alcoholic drinks, but inevitably, someone tries to order another round or says, 'Why don't you want to do this?' (II) 
Another participant recalled missing out on a family gettogether because a family member announced that she was pregnant at the event and she did not want to show her family how upset she was: 'I so distinctly remember sitting in my bedroom and just crying... I knew I couldn't leave our room' (FG).

\section{Feeling dismissed by health service providers}

Several participants recounted feeling disappointed with the service they had received from their mental health provider. One woman recounted her encounter with a mental health professional specialising in infertility:

She gave me quite a cookie cutter approach to her counseling... like, you're going through infertility so you must be experiencing this and this and this. I was like 'Oh no, I am not experiencing that.' (II)

In addition, women described feeling dismissed by their reproductive healthcare service providers who sometimes minimised the emotional pain associated with what they were experiencing. One woman seeking care for a suspected miscarriage remembered:

My family doctor... He told me he didn't think I was miscarrying. He also said, 'If you are, then it's not really a big deal because you're young and you can keep trying. I've had patients that have been trying for years and years and years and you really shouldn't be worried yet'. And that's really difficult and frustrating to hear. (II)

Mental health professionals echoed the same sentiments, remarking that younger women are especially prone to receiving dismissive comments from the medical community:

Women with a female factor diagnosis who are very, very young often have a very hard time in the treatment process because they're often not taken seriously...I've heard many specialists tell them, 'You have lots of time, don't worry about it, it'll happen for you', which can be really quite dismissive of their feelings and their coping. (MHP)

\section{Summary}

Through this theme, it became clear that women's tendency to distance themselves from others and the activities they used to enjoy was partly related to a desire to avoid having to discuss their infertility with others, whom they generally found to be unhelpful in providing emotional support. Several women perceived a lack of compassion and understanding of the emotional aspects of infertility among both mental health and reproductive health professionals, leading them to feel truly alone in coping with their emotional pain.

\section{Therapeutic techniques used by mental health professionals}

All the mental health professionals reported using an eclectic approach to psychotherapy for infertility. They combined techniques from a number of different therapeutic approaches, including but not limited to the following: supportive therapy, cognitive-behavioural therapy (CBT), dialectical behavioural therapy (DBT), acceptance and commitment therapy (ACT), compassionfocused therapy, mindfulness, counselling, eye movement desensitisation and reprocessing, cognitive processing therapy, emotion-focused therapy (EFT), solutionfocused therapy, psychodynamic therapy, interpersonal psychotherapy (IPT), internal family systems, expressive therapy, existential therapy and upside down therapy. A short description of these therapeutic approaches is given in table 2.

CBT, DBT and mindfulness-based approaches stood out as the most used, although always in combination with others. Participants also reported applying CBT with caution: 'At times I might reach for CBT...but really I have to be very careful because...the distress that a woman is experiencing... are a normal response to an abnormal situation' (MHP 1). A second mental health professional echoed these concerns: 'There's nothing more invalidating to a woman who's experienced multiple losses than when you sit down with her and would say, ... 'So, what are the cognitive distortions?'...It's invalidating' (MHP 1). Other mental health professionals found that CBT was not at all useful in the context of infertility:

CBT and solution-focused [therapy] are pretty useless with this population... and I know the evidence doesn't support that because that's the only theory [CBT] that has any evidence-based research behind it, which creates its own bias in and of itself. (MHP 11)

Several mental health professionals reported using mindfulness techniques, particularly for addressing anxiety, with one reporting: 'We do a lot of emotion regulation and mindfulness grounding and learning to breathe and settle their anxiousness' (MHP 3). A second professional stated: 'Women really find it helpful to learn just ways of the balance between accepting, and letting go, and having hope, and I think... that can be found through mindfulness' (MHP 12). Others reported combining a mindfulness approach with traditional CBT: 'I often and typically in practice use mindfulness and CBT together' (MHP 13). Still others endorsed using mindfulness in the context of other therapeutic approaches that include mindfulness as part of its focus, including ACT and DBT, a CBT-based approach that incorporates mindfulness and other skills aimed at promoting distress tolerance: 'I use... DBT techniques because the amount of distress that I see in these women is profound' (MHP 14).

Several mental health professionals emphasised that flexibility was critical and that adherence to a therapeutic approach should not interfere with responding to a client's needs in any given session. One therapist explained: 'Client centered is so important...some people just want to be heard and validated, and that's why they're 
Table 2 Brief description of therapeutic approaches mentioned by mental health professionals

\begin{tabular}{|c|c|}
\hline Therapeutic approach & Therapeutic focus \\
\hline Acceptance and commitment therapy ${ }^{37}$ & $\begin{array}{l}\text { Teaching mindfulness strategies to decrease avoidance and increase focus on the } \\
\text { present }\end{array}$ \\
\hline Cognitive-behavioural therapy ${ }^{33}$ & Changing cognitive distortions and changing behaviours to improve mental health \\
\hline Cognitive processing therapy ${ }^{47}$ & Challenging unhelpful beliefs related to trauma \\
\hline Counselling $^{48}$ & Providing emotional support to clients experiencing crisis, typically unstructured \\
\hline Dialectical behavioural therapy ${ }^{34}$ & $\begin{array}{l}\text { Improving emotion regulation and improving relationships; is highly successful for } \\
\text { borderline personality disorder }\end{array}$ \\
\hline Emotion-focused therapy ${ }^{35}$ & Increasing the awareness, acceptance, expression and regulation of emotion \\
\hline Existential therapy ${ }^{49}$ & $\begin{array}{l}\text { Focuses on concepts related to human existence, such as death, responsibility and } \\
\text { the meaning of life }\end{array}$ \\
\hline Expressive therapy ${ }^{50}$ & Using creative arts to facilitate the exploration of difficult emotions \\
\hline $\begin{array}{l}\text { Eye movement desensitisation and } \\
\text { reprocessing }\end{array}$ & $\begin{array}{l}\text { Encouraging the patient to recall a traumatic memory while simultaneously moving } \\
\text { their eyes from side to side }\end{array}$ \\
\hline Internal family systems ${ }^{52}$ & $\begin{array}{l}\text { Identifying and addressing the multiple 'subpersonalities' or families that form a } \\
\text { person's identity }\end{array}$ \\
\hline Interpersonal psychotherapy ${ }^{43}$ & Resolving interpersonal problems and facilitating social support \\
\hline Mindfulness-based approaches ${ }^{53}$ & $\begin{array}{l}\text { Fostering greater awareness, attention and acceptance of present moment } \\
\text { experiences }\end{array}$ \\
\hline Psychodynamic therapy ${ }^{54}$ & $\begin{array}{l}\text { Increasing client awareness of the unconscious influences on their past and present } \\
\text { behaviour }\end{array}$ \\
\hline Solution-focused therapy ${ }^{55}$ & $\begin{array}{l}\text { Helping the client identify resources that will help them develop a realistic and } \\
\text { sustainable solution to the problems they are facing }\end{array}$ \\
\hline Upside down therapy ${ }^{56}$ & $\begin{array}{l}\text { Incorporating elements of play to increase distance between oneself and the content } \\
\text { of one's thoughts }\end{array}$ \\
\hline
\end{tabular}

coming to therapy' (MHP 7). Another expressed a similar sentiment: 'everyone is different...looking at what are their goals... so very client-centered focus' (MHP 9).

In sum, all mental health professional participants reported using techniques from more than one psychotherapeutic approach in order to address the psychological symptoms associated with infertility and to target the specific needs of each client.

\section{DISCUSSION}

The purpose of the current study was to gain a deeper understanding of infertility-related distress as well as gather information about which psychotherapeutic approaches were being used by mental health professionals for the treatment of infertility-related distress. The ultimate aim was to inform the development of an intervention better tailored to infertility and more effective than currently available ones. While some of the identified themes and subthemes are common to mood and anxiety disorders unrelated to infertility, the results of the current study also highlighted several challenges that are clearly unique to infertility. Women's reports, corroborated by the accounts of mental health professionals specialising in infertility-related distress, paint a picture of infertility-related distress in which one is highly preoccupied and emotionally invested in the day-to-day occurrences of the menstrual/treatment cycle, leading to high anxiety and fluctuating mood. As they are preoccupied with their current efforts and wish to avoid having to explain themselves to others or to submit themselves to others' pregnancies and children, they become more reclusive and spend less time engaged in activities that previously enriched their lives. They worry about who they will be and what their lives will look like if they never conceive. At the same time, at home, women are struggling to connect with their partner as they do not always find themselves to be on the same page with regard to various reproductive events and/or decisions to be made. In a subset of women, these emotional struggles contribute to clinical mental health problems over time and, in some, the complete dissolution of their relationship. Below, we review each of the identified themes in greater detail and compare our findings with those of other studies.

Anxiety emerged as one of the most prominent features of infertility-related distress, consistent with previous findings from other studies in which anxious rumination was reported to be a common feature of infertility. ${ }^{22} 23$ A few studies have also reported on women's narrowed focus on infertility to the exclusion of other activities, as well as excessive information seeking as behavioural features of anxiety. ${ }^{24-26}$ In this study, these subthemes were more prominent, and we suspect that the inclusion of mental 
health professionals, providing an outsider's perspective, was a unique feature in the current study that may have facilitated the identification of these subthemes.

With regard to the second theme, mood disturbance, other researchers have also reported on the 'emotional rollercoaster' of infertility, as well as the loss of control that women frequently experience. ${ }^{622} 2728$ Emotional exhaustion and burnout have also been reported as a common feature of infertility, resulting from the chronic exposure to the emotional ups and downs of infertility. ${ }^{26}{ }^{29}$ This finding is consistent with the high rate of clinical depression seen among women struggling with infertility. ${ }^{7910}$ The third theme-threat to self-esteem, identity and purpose-is somewhat similar to previous reports that women's view of themselves and their future identities are challenged by infertility, leading to feelings of role loss or role failure and the development of a negative self-perception. ${ }^{626}{ }^{27}$ Pedro and Andipatin ${ }^{30}$ also reported on women's tendency to blame themselves for their infertility. Finally, the broad themes of deterioration of the couple, ${ }^{22} 2328$ and of weakened social support systems $^{27}{ }^{28}$ have been previously identified. However, the identification of specific subthemes within these broader issues is unique to the current study and helps to inform the identification and development of more effective psychotherapies directly targeting infertilityrelated distress. The subtheme relating to negative interactions with healthcare providers adds to the findings of previous studies ${ }^{31} 32$ and highlights the need for increased awareness and education among healthcare providers in addressing the emotional aspect of infertility with sensitivity and compassion.

Mental health professionals reported using an array of techniques borrowed from a range of psychotherapy approaches, some more evidence based than others, to address the unique challenges associated with infertilityrelated distress. CBT, arguably the psychotherapeutic approach most supported by research evidence for the treatment of depression and anxiety unrelated to infertility ${ }^{33}$ was met with disdain by some and cautious acknowledgement of its potential benefits by others. Specific concerns about CBT related to its focus on 'cognitive distortions' as being invalidating of the very natural emotions resulting from infertility. Approaches incorporating mindfulness, commonly termed 'thirdwave' psychotherapy approaches, were mentioned numerous times as being helpful, including ACT, DBT and mindfulness-based cognitive therapy, all of which are supported by growing bodies of research evidence for distress unrelated to infertility. ${ }^{33} 34$ Other therapy approaches mentioned, such as EFT, upside down therapy and existential therapy, have modest to no research support as of yet. ${ }^{35} 36$

These findings, in combination with recent metaanalytical evidence suggesting that the efficacy of current psychotherapeutic approaches to infertility is modest, ${ }^{15}$ perhaps reflect a need for a new psychotherapeutic approach that combines techniques from various approaches to create a more tailored intervention that addresses the unique psychological challenges identified here. While cognitive restructuring, progressive muscle relaxation, and mindfulness meditation are the mostused and tested approaches to date for the treatment of infertility-related distress, their efficacy in this population is limited. ${ }^{15}$ Several other approaches mentioned by the mental health professionals may better target the unique aspects of infertility-related distress. For example, some of the techniques used in DBT aimed at improving distress tolerance ${ }^{34}$ may help women cope with intense distress during medical procedures or after very upsetting news. The interpersonal effectiveness skills taught in DBT may also help individuals appropriately interact with the people in their lives who say unhelpful or upsetting things related to their infertility.

ACT, mentioned by several mental health professionals in our study, may be useful in addressing the avoidance of infertility reminders, which emerged as one of the subthemes of infertility-related anxiety, as ACT encourages women to engage in activities that align with their values, in spite of the distress that doing so may cause. ${ }^{37}$ For example, a woman who highly values being a supportive sister will be encouraged to work up to going to her sister's baby shower. Importantly, cognitive strategies and mindfulness exercises are first introduced to equip clients with the tools needed to cope with the distress they encounter through the process of exposure. To date, studies conducted in the Middle East have applied ACT to infertility-related distress with promising results, ${ }^{38-40}$ though it has yet to be tested in North America.

Several of the mental health professionals highlighted the use of mindfulness-based approaches. Although mindfulness approaches have proven to be of limited efficacy for infertility-related distress, one mindfulnessbased approach that has yet to be applied to infertility is loving-kindness meditation (LKM) ${ }^{41}$ which seems to map on well to both shame/self-blame and severed relationships with others. LKM is a Buddhist practice aimed at increasing compassion towards self and others. As a first step, one meditates while focusing on statements that promote self-love and self-compassion (eg, 'May I be free from mental suffering or distress'), while attempting to let go of any self-judgement or self-hatred. Next, thoughts and statements centre around an elderly loved one, then a close loved one, next a neutral person, and, finally, someone with whom you have a difficult relationship or feel bitterness towards. Mounting research ${ }^{42}$ suggests that LKM increases both positive self-regard as well as positive feelings towards others. In infertility, it may therefore be used to reduce feelings of shame related to the diagnosis while also improving relationships with others who fail to provide the emotional support that was expected or hoped for.

IPT, which was also mentioned by several mental health professionals, may also be an effective approach to improving a woman's interpersonal relationships within the context of infertility. IPT is a time-limited, 
evidence-based therapy that uses techniques such as communication analysis and role-playing to address four main interpersonal issues: interpersonal disputes, role transitions, grief and interpersonal deficits. ${ }^{434}$ Within the context of infertility, interpersonal disputes may include disagreements with one's partner about next steps to take in fertility treatments or negative interactions with loved ones who inadvertently make unhelpful comments. 'Role transitions' may also be relevant for women contemplating stopping treatments and who are trying to make peace with living a child-free life. Finally, 'grief' is clearly applicable to negative pregnancy test outcome or miscarriage. To our knowledge, a single pilot study has tested IPT for infertility-related distress, with promising results. ${ }^{45}$

Though CBT has been applied to infertility in a number of studies, with limited results, there are a number of CBTbased techniques that have yet to be used but that may address some of the specific infertility-related psychological challenges raised in this study. Specifically, given the prominence of anxious rumination and excessive information seeking, the incorporation of 'worry time' may be warranted. 'Worry time' is a technique that is commonly used in CBT for generalised anxiety disorder and involves having the client set aside a certain amount of time daily (eg, 30 min once or twice daily) to devote to their ongoing worries. ${ }^{33}{ }^{46}$ In the context of infertility, this time could be used to research potential treatments, budget for fertility treatments or simply contemplate what life might be like without children. Whenever an infertility-related worry pops up outside of 'worry time', women would be encouraged to jot down their concerns on a notepad, to be considered further during the next worry time. While this technique may seem counterintuitive, research has found it to be effective in reducing the amount of time spent ruminating overall. ${ }^{3346}$

A few limitations are worth mentioning. Our sample was relatively homogeneous, being largely Caucasian and of high socioeconomic status, potentially limiting the generalisability of our findings to the larger population. All participants were also in heterosexual relationships, perhaps preventing the discovery of themes specific to same-sex couples. Despite these limitations, our study is strengthened by its patient-oriented approach and its inclusion of mental health professionals specialising in infertility.

Ultimately, it is hoped that the careful consideration of the unique aspects of infertility-related distress will result in the most effective intervention possible for this population. The findings of the current study highlight the need to address individuals' struggles with anxiety and depressive mood while also repairing fractured couple and interpersonal relationships, facilitating continued engagement in activities that enriched one's life before the diagnosis of infertility and that help to increase resilience in the face of the stressful circumstances surrounding infertility.

Acknowledgements The authors would like to express their gratitude to the women and the mental health professionals who gave their invaluable time to contribute to this study. Special thanks go to the panel of women and the team at the Women's Mental Health Research lab for their continuous support.

Contributors LD contributed to study design, data collection, analysis, and drafting and revising the manuscript. NN-M contributed to analysis and revising the manuscript. $A A B$ contributed to data collection and revising the manuscript. JLG contributed to study design, data collection, analysis and revising the manuscript. All authors approved the final version of the manuscript. As the guarantor, JLG accepts responsibility for the overall content of the manuscript.

Funding LD's salary and this study were funded by the Saskatchewan Health Research Foundation Patient Oriented Research Leader Award (grant \#4577). JLG is supported by a Tier II Canadian Institutes of Health (CIHR) Canada Research Chair.

Disclaimer Funders and institutions played no role in the development and implementation of this study.

Competing interests None declared.

Patient and public involvement Patients and/or the public were involved in the design, or conduct, or reporting, or dissemination plans of this research. Refer to the Methods section for further details.

Patient consent for publication Not required.

Ethics approval This study was conducted between November 2019 and February 2020 and approved by the Research Ethics Board of the University of Regina (REB\# 2019-137). All women with infertility provided written informed consent and received a $\$ 10$ gift card. Mental health professionals provided oral consent over the phone and did not receive compensation. All participants gave consent to be audio-recorded.

Provenance and peer review Not commissioned; externally peer reviewed.

Data availability statement No data are available. The data (transcripts and audios files) for this study cannot be made available to the public due to ethical reasons. However, the original data are reflected in the results which provide a rich and thick description of the contents of the interviews through quotations.

Open access This is an open access article distributed in accordance with the Creative Commons Attribution Non Commercial (CC BY-NC 4.0) license, which permits others to distribute, remix, adapt, build upon this work non-commercially, and license their derivative works on different terms, provided the original work is properly cited, appropriate credit is given, any changes made indicated, and the use is non-commercial. See: http://creativecommons.org/licenses/by-nc/4.0/.

ORCID iD

Jennifer L Gordon http://orcid.org/0000-0001-6401-6827

\section{REFERENCES}

1 Bushnik T, Cook JL, Yuzpe AA, et al. Estimating the prevalence of infertility in Canada. Hum Reprod 2012;27:738-46.

2 Sharlip ID, Jarow JP, Belker AM, et al. Best practice policies for male infertility. Fertil Steril 2002;77:873-82.

3 World Health Organization. Sexual and reproductive health - Multiple definitions of infertility 2020, 2020. Available: https://www.who.int/ reproductivehealth/topics/infertility/multiple-definitions/en/

4 Agarwal A, Mulgund A, Hamada A, et al. A unique view on male infertility around the globe. Reprod Biol Endocrinol 2015;13:37.

5 Bai C-F, Cui N-X, Xu X, et al. Effectiveness of two guided selfadministered interventions for psychological distress among women with infertility: a three-armed, randomized controlled trial. Hum Reprod 2019;34:1235-48.

6 Born SL, Carotta CL, Ramsay-Seaner K. A multicase study exploring women's narratives of infertility: Implications for counsellors. Qual Rep 2018;23:2992-3003.

7 Chen T-H, Chang S-P, Tsai C-F, et al. Prevalence of depressive and anxiety disorders in an assisted reproductive technique clinic. Hum Reprod 2004;19:2313-8.

8 Kee BS, Jung BJ, Lee SH. A study on psychological strain in IVF patients. J Assist Reprod Genet 2000;17:445-8.

9 Nelson CJ, Shindel AW, Naughton CK, et al. Prevalence and predictors of sexual problems, relationship stress, and depression in female partners of infertile couples. J Sex Med 2008;5:1907-14.

10 Volgsten H, Skoog Svanberg A, Ekselius L, et al. Prevalence of psychiatric disorders in infertile women and men undergoing in vitro fertilization treatment. Hum Reprod 2008;23:2056-63.

11 Chernoff A, Balsom AA, Gordon JL. Psychological coping strategies associated with improved mental health in the context of infertility. Arch Womens Ment Health 2021;24:73-83. 
12 Freeman EW, Boxer AS, Rickels K, et al. Psychological evaluation and support in a program of in vitro fertilization and embryo transfer. Fertil Steril 1985;43:48-53.

13 Benyamini Y, Gozlan M, Kokia E. Women's and men's perceptions of infertility and their associations with psychological adjustment: a dyadic approach. Br J Health Psychol 2009;14:1-16.

14 Oddens BJ, den Tonkelaar I, Nieuwenhuyse H. Psychosocial experiences in women facing fertility problems--a comparative survey. Hum Reprod 1999;14:255-61.

15 Frederiksen Y, Farver-Vestergaard I, Skovgård NG, et al. Efficacy of psychosocial interventions for psychological and pregnancy outcomes in infertile women and men: a systematic review and meta-analysis. BMJ Open 2015;5:e006592.

16 Vaismoradi $\mathrm{M}$, Jones $\mathrm{J}$, Turunen $\mathrm{H}$, et al. Theme development in qualitative content analysis and thematic analysis. JNEP 2016;6:100-10.

17 Creswell J, Poth C. Qualitative inquiry and research design: choosing among five approaches. California, USA: SAGE Publications Inc, 2018.

18 Qualtrics Inc. Qualtrics. Provo, Utah, USA: Qualtrics Inc, 2019.

19 Bailey DC. Women and Wasta: the use of focus groups for understanding social capital and middle Eastern women. Qual Rep 2012:17:1-18.

20 Tong A, Sainsbury P, Craig J. Consolidated criteria for reporting qualitative research (COREQ): a 32-item checklist for interviews and focus groups. Int J Qual Health Care 2007;19:349-57.

21 QSR International Pty Ltd. NVivo qualitative data analysis software. Version 10.2019.

22 Born SL, Preston JJ. The fertility Invetory and Infertility-related stress: a case study. Qual Rep 2016;21:497-520.

23 Donkor ES, Naab F, Kussiwaah DY. "I am anxious and desperate": psychological experiences of women with infertility in The Greater Accra Region, Ghana. Fertil Res Pract 2017;3:6.

24 Porter M, Bhattacharya S. Helping themselves to get pregnant: a qualitative longitudinal study on the information-seeking behaviour of infertile couples. Hum Reprod 2008;23:567-72.

25 Slauson-Blevins KS, McQuillan J, Greil AL. Online and in-person health-seeking for infertility. Soc Sci Med 2013;99:110-5.

26 Becker G, Nachtigall RD. Eager for medicalisation: the social production of infertility as a disease. Sociol Health \& IIIness 1992;14:456-71.

27 Berger R, Paul MS, Henshaw LA. Women's experience of infertility: A multi-systemic Perspective. J Int Womens Stud 2013;14:54-68.

28 Dierickx S, Rahbari L, Longman C, et al. 'I am always crying on the inside': a qualitative study on the implications of infertility on women's lives in urban Gambia. Reprod Health 2018;15:151.

29 Ghavi F, Jamale S, Mosalanejad L, et al. A study of couple burnout in infertile couples. Glob J Health Sci 2015;8:158-65.

30 Pedro A, Andipatin M. A qualitative exploration of South African Women's psychological and emotional experiences. J Prev Med 2014;4:327-37.

31 Malin M, Hemmink E, Räikkönen O, et al. What do women want? women's experiences of infertility treatment. Soc Sci Med 2001;53:123-33.

32 Nachtigall RD, Castrillo M, Shah N, et al. The challenge of providing infertility services to a low-income immigrant Latino population. Fertil Steril 2009;92:116-23.

33 Beck J. Cognitive behavior therapy: basics and beyond. 2nd ed. New York: Guilford Press, 2012

34 Linehan M. DBT skills training manual. 2nd Edition. New York: The Guildford Press, 2015.

35 Greenberg LS. Emotion-focused therapy. Clin Psychol Psychother 2004:11:3-16.
36 APA Presidential Task Force on Evidence-Based Practice. EvidenceBased practice in psychology. Am Psychol 2006;61:271-85.

37 Harris R. ACT made simple. 2nd ed. Oakland, Canada: New Harbiner Publications, Inc, 2019.

38 Hosseinpanahi M, Mirghafourvand M, Farshbaf-Khalili A, et al. The effect of counseling based on acceptance and commitment therapy on mental health and quality of life among infertile couples: a randomized controlled trial. J Educ Health Promot 2020;9:251-51.

39 Rahimi E, Attarha M, Majidi A. Effect of acceptance and commitment therapy on the quality of life in infertile women during treatment: a randomized control trial. International Journal of Women's Health and Reproduction Sciences 2019;7:483-9.

40 Haji-Adineh S, Rafiean S, Tavakoli S. The effectiveness of acceptance and commitment therapy on optimism about life and psychological well-being in infertile women. Int J Body Mind Culture 2019;6:201-8.

41 Hofmann SG, Grossman P, Hinton DE. Loving-kindness and compassion meditation: potential for psychological interventions. Clin Psychol Rev 2011;31:1126-32.

42 Shonin E, Van Gordon W, Compare A, et al. Buddhist-derived loving-kindness and compassion meditation for the treatment of psychopathology: a systematic review. Mindfulness 2015;6:1161-80.

43 Weissman M, Markowitz JC, Klerman GL. The guide to interpersonal psychotherapy: Upated and expanded edition. New York: Oxford University Press, 2018.

44 Markowitz JC, Weissman MM. Interpersonal psychotherapy: principles and applications. World Psychiatry 2004;3:136-9.

45 Koszycki D, Bisserbe J-C, Blier P, et al. Interpersonal psychotherapy versus brief supportive therapy for depressed infertile women: first pilot randomized controlled trial. Arch Womens Ment Health 2012;15:193-201.

46 Borkovec TD, Wilkinson L, Folensbee R, et al. Stimulus control applications to the treatment of worry. Behav Res Ther 1983:21:247-51.

47 Galovski TE, Wachen JS, Chard KM, et al. Cognitive processing therapy. In: Schnyder U, Cloitre M, eds. Evidence based treatments for trauma-related psychological disorders. Cham: Springer, 2015: 189-203.

48 McLeod J. An introduction to counselling. 3 ed. Berkshire: Open University Press, 2003.

49 Frew J, Spiegler MD, eds. Contemporary psychotherapies for a diverse world: first revised edition. 1st ed. Milton: Routledge, 2012.

50 Machtinger EL, Lavin SM, Hilliard S, et al. An expressive therapy group disclosure intervention for women living with HIV improves social support, self-efficacy, and the safety and quality of relationships: a qualitative analysis. J Assoc Nurses AIDS Care 2015;26:187-98.

51 Wilson SA, Becker LA, Tinker RH. Eye movement desensitization and reprocessing (EMDR) treatment for psychologically traumatized individuals. J Consult Clin Psychol 1995;63:928-37.

52 Campbell A. Internal family systems therapy with children Lisa Spiegel. Aust N Z J Fam Ther 2019;40:282-4.

53 Creswell JD. Mindfulness interventions. Annu Rev Psychol 2017;68:491-516.

54 Kudler HS, Blank AS, Krupnick JL. Psychodynamic therapy. In: Foa EB, Keane FMJ, eds. Effective treatments for PTSD: practice guidelines from the International Society for traumatic stress studies. New York: The Guilford Press, 2000: 176-98.

55 O'Connell B, ed. Solution-Focused therapy. 3 ed. London: SAGE Publications Ltd, 2012.

56 Seif M, Winston S. Upside-Down psychotherapy: breaking the rules with our OCD clients. psychotherapy Networker. Wisconsin: PESI, Inc, 2016 . 